\title{
A STUDY ON SOME OPERATIONAL PARAMETERS AFFECTING THE PERFORMANCE OF EGYPTIAN WHEAT MILLING PROCESSES
}

\author{
Fouda, T* A. Derbala* M. Darwesh ${ }^{* *}$ S. Elsabaei***
}

\section{ABSTRACT}

The experimental work was carried out in Defra at Gharbia governorate, Egypt, during 2014 to 2016.The wheat milling production line consists of many stages such as (receiving, cleaning, separator, tempering ,milling, processes).The experiments were monitoring the performance of wheat milling production line and determined the optimum parameters and conditions for operating production line under using Egyptian wheat. The physical characteristics for wheat kernel and flour were tested, Also adjustments the machines through all line to maximize milling efficiency addition to give high the quality of the final product. The results showing the physical properties of wheat sample, the length ranged from 6.48 to $7.43 \mathrm{~mm}$, width were 3.16 to 4.02 and seeds thickness ranged from $3.29 \mathrm{~mm}$ to $3.67 \mathrm{~mm}$. while the maximum value of 1000 grains weight about $50.60 \mathrm{~g}$.The maximum value of cleaning efficiency at the third machine when using Egyptian wheat. The cleaning efficiency ranged from 94.00 to $99.80 \%$. The cleaning efficiencies for separator, dry stoner and tiruer machines must to be more than 99\%. The results obtained from damping condition showed increased the moisture content from 10.50 to $13.50 \%$ at the first condition to reach $15.5 \%$ at the second condition. Also increased 1000 grains weight, form 50.6 to $61.40 \mathrm{~g}$. at the first condition to reach at the second condition to $65.20 \mathrm{~g}$. While hectoliter weight decreased from 80.90 to $78.20 \mathrm{Kg} / \mathrm{m}^{3}$ at the first condition to reach at the second condition to $77.50 \mathrm{Kg} / \mathrm{m}^{3} \%$. Also the break system must adjust milling machine to finished the standard break release percentage value with $30 \%$, as the last stage.

Keywords: Wheat, The physical characteristics, milling processes, damping condition and break system test

\footnotetext{
*Prof of Agric. Eng. Dept., Faculty of Agriculture, Tanta Univ.

** Assoc. Prof. of Agric. Eng. Dept., Faculty of Agriculture, Tanta Univ.

***Postgraduate student of Agric. Eng. Dept., Faculty of Agriculture, Tanta Univ.
} 


\section{INTRODUCTION}

s wheat arrives in the mill it is passed through a
cleaning process to remove coarse impurities and is then stored
according to its quality, the wheat grain into its constituents (bran, germ and endosperm). The Milling process is break the wheat grains and scrape the endosperm away from the bran. This process is repeated several times until it becomes into flour containing as little bran or germ as possible Feillet, (2000) reported that, the starch represents $67-68 \%$ of whole wheat grain and between $78 \%$ and $82 \%$ of the flour which composed of amylose (26-28\%) and amylopectin (72-74\%). The effects of normal and hard milling and different conditioning times on flour properties of Egyptian wheat Sakha 94 and Gemmeiza 11 were studied. Fang and Campbell (2003) noted five purposes of conditioning as:

(i) to toughen the bran, reducing formation of bran powder; (ii) to soften the endosperm, enhancing its mill ability and reducing the power consumed by the reduction rolls; (iii) to facilitate separation of bran from endosperm, reducing the power consumption of the break rolls and consequently reducing evaporative losses; (iv) to ensure easy and accurate sifting of stocks; and (v) to ensure the endosperm moisture content is sufficient to give a final flour moisture content of around 14$15 \%$.

(Kihlberg et al., 2004) stated that, the most important consideration in producing whole grain flour is selecting the milling process that will be used. Indeed milling technique may have a greater impact on whole wheat bread quality than the quality of wheat used for producing the flour or the formulation of the bread it self Campbell et al. (2007a) in an evaluation of fundamental parameters influencing milling performance made the following comments: Flour millers produce mainly for bakers, whose principal requirement is for a flour of consistent quality. Also developed models based on the breakage equation for roller milling to predict the output particle size distribution .Johan Karlsson (2008) reported that the relation between the gap size 
between the rollers and the particle size output, a bigger experiment was carried out. The gap between the rollers where changed in 7 steps, from a big gap and then in increments down to a very small gap. The product grinded from the respective experiments where then collected in separate bins, and then the particle size distribution was measured o_ine with the help of the sensor. (Gomez et al., 2010) increase in firmness, chewiness, and yellowness when more coarse particle sizes were used. In a sensory evaluation, these changes were not favored by consumers; the best sensory acceptability was reached when finer particle sizes were used. The aim of this research to optimizing the operational parameters of a wheat milling plant to minimize the energy and maximized the milling efficiency. Also to investigate the relationship between the wheat kernel properties, milling machine line adjustment and the qualities of the grinded wheat.

\section{MATERIALES AND METHODES}

This study was conducted at Tanta milling company in Defra ,Gharbia province ,Egypt during 2014-2016. The Egyptian wheat samples (Gemmeiza 9) selection to evaluate the impact of the physical characteristics on milling processes. The experiments were designed to adjust the operational parameters, recognize and test a possible applicant for the milling plant, addition to evaluate and test the quality of the final product. The descriptions of the experiments are presented below.

\section{Materials}

Wheat characteristics: The kernels produced can have different sizes, shapes, amounts of gluten, and textures. Each variety is more suitable for different purposes according to its specific traits. Once these various kernels are extracted from the plant, then the milling process can begin. Grain of wheat consists basically of three essential parts. (The Bran = This is the outer cover or skin.-The Germ $=$ This is the embryo of a new plant.-The Endosperm = From which flour is made).as showing in Fig. 1 also Table (1).showing Laboratory Analysis of some physical properties of tested wheat kernel. 
Table (1) Laboratory Analysis of some physical properties of wheat kernel

\begin{tabular}{|c|c|c|c|}
\hline Physical properties & Egypt & \multirow{7}{*}{\multicolumn{2}{|c|}{\begin{tabular}{c|c|} 
Bran $14 \%$ \\
\end{tabular}}} \\
\hline Moisture Content \% & 10.5 & & \\
\hline Hectoliter Weight, $\mathrm{Kg} / \mathrm{m}^{3}$ & 80.9 & & \\
\hline 1000 Grains Weight, g. & 50.6 & & \\
\hline Thickness of grain mm & 3.35 & & \\
\hline Width of grain mm & 4.02 & & \\
\hline Length of grain $\mathrm{mm}$ & 7.43 & & \\
\hline Immature grain \% & 0.2 & & \\
\hline Foreign matters \% & 0.08 & & \\
\hline Broken \% & 0.1 & & $2.5 \%$ \\
\hline
\end{tabular}

\section{Wheat milling plant:}

Fig. 1 Structure of grain wheat

The purpose of the miller must be to isolate the endosperm in as pure a state as possible, so that it can be ground into flour containing as little bran or germ. The wheat miller consists of many stages such as (receiving, cleaning, separator, tempering, milling, grading, weighing and packing processes). The flour milling process can be divided into four main stages as showing in Fig.2. Also (Fig.3). showing Front page for monitoring and control system for wheat milling plant.

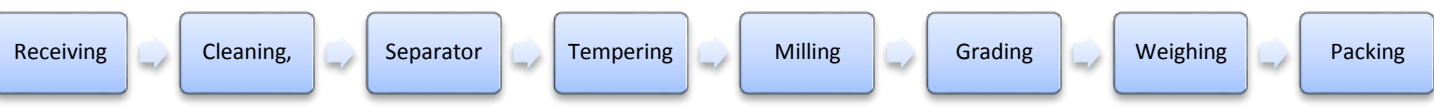

Fig 2: A schematic diagram for wheat milling process

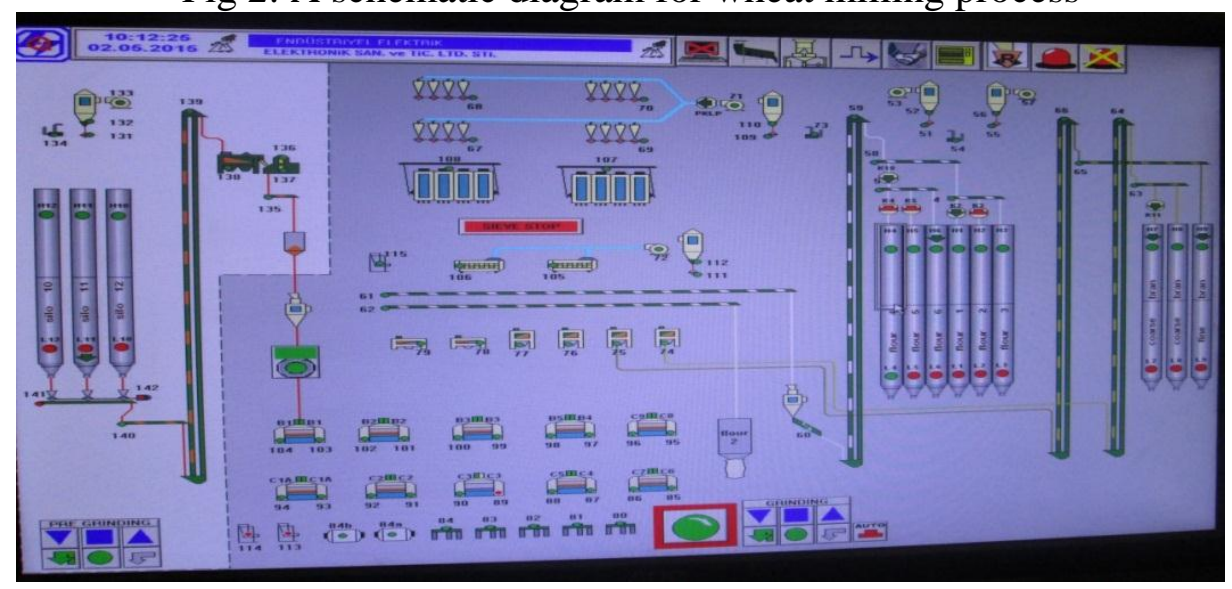

(Fig.3). Front page for monitoring and control system for wheat milling plant 
The receiving processes: wheat were obtained from many sources and was delivered in various ways, the intake (Fig.4). it used in order to reception the wheat and gives it to bucket elevator, wheat before being stored in the silo (Fig.5).

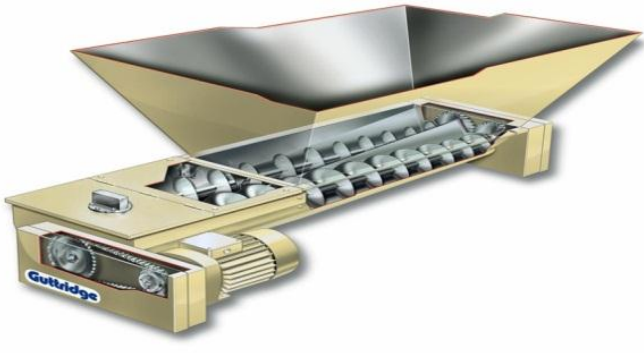

(Fig.4). Intake hoper

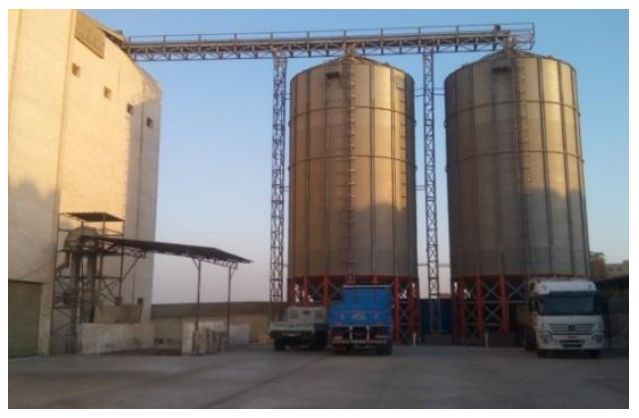

(Fig.5). Silo

The cleansing process: involves passing the grain through several machines that will remove any contamination in the batch of grain. These machines include a separator, (Fig.6). dry-stoner, (Fig.7). and triuer. After passing through this process you can rest assured that the grain is clear of any other substances.

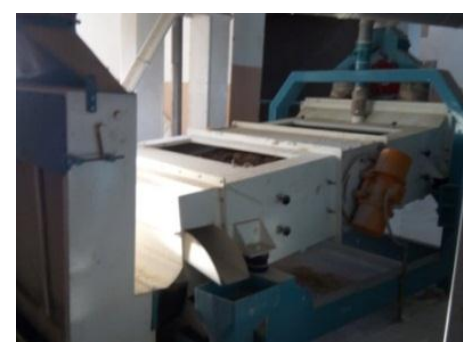

(Fig.6). Separator

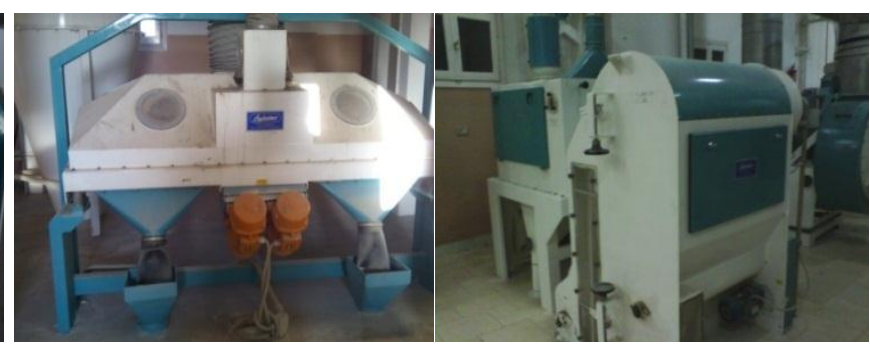

(Fig.7). Dry-stoner,

(Fig.8).Triuer

The conditioning procedure: mixes water with the grain to get the right moisture level as showing Fig 9 and 10. This will make the grain easier to mill. After cleaning and conditioning, the grain is finally ready to begin the milling process.

The wheat damping equation:

$$
M C=\frac{M-D}{M} \times 100
$$

Where: MC Wheat seed moisture content, \%

M: Wheat seed sample mass, g, and D: Wheat seed sample mass after drying, g. 


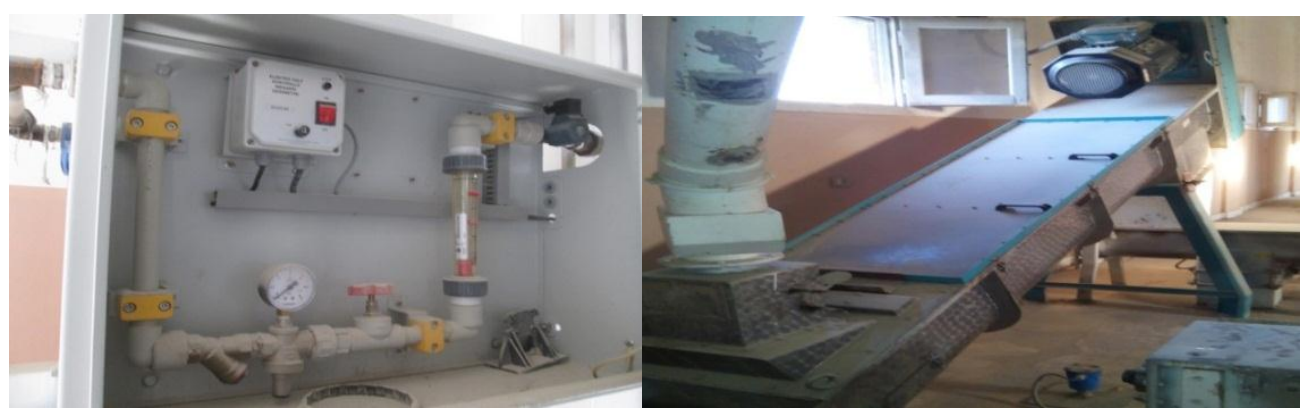

(Fig.9). Water adjust amount and pressure (Fig.10) damping conditioning

The milling process: The grain starts off by going through a pair of rollers turning in opposite directions. There are several different types of rolling systems used to obtain the different desired results. These rollers will cause the inner endosperm to be released. Then, the opened grain will pass through sieves in order to separate the finer grains. The particles that pass through the finest sieve are considered flour. The particles that do not fall through this sieve continue to go through rollers until it is broken down into flour as showing in Fig.11

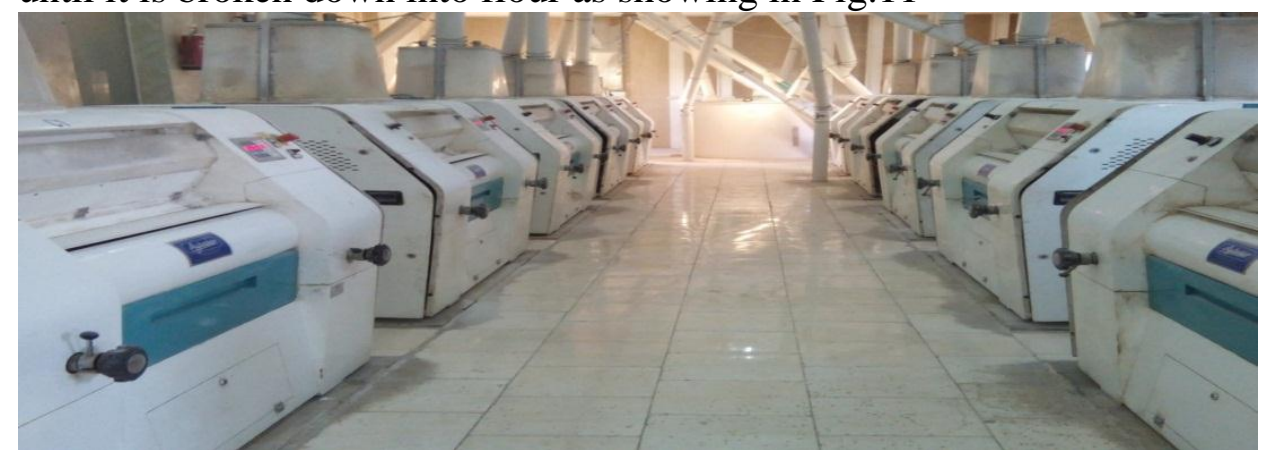

(Fig.11). The milling wheat machines (Break and reduction systems)

\section{-Factors under this study}

Many factors were affecting on the wheat miller performance, productivity and efficiency during milling processes. Some of these factors are related to the wheat quality and others are related to miller machines. The performance of miller was measured under the following parameters:

- Three batches grade from Egyptian variety

- The amount of water added in first conditions (200 Liter per hours for tempering time about 16 hours and second conditions ( 250 Liter per 
hours for tempering time about) adjusted the amount of water according to grin moisture content

- Fife different the arrangement of the roll cylinders clearance and sieves meshes at break stage

- Four cylinders positions (sharp to sharp, dull to dull, sharp to dull and dull to sharp)

\section{Measurements}

Wheat grin testing: Main dimensions of the seeds length, width and thickness moisture content, 1000 grains weight and hectoliter weight were measured

\section{-Reception and storage of wheat stage.}

Three Silo for reception, storage and mix of wheat to provide the miller by wheat and to keep running of different types of wheat according to the miller's requirements.

\section{-Cleaning efficiency}

The Cleaning efficiency were obtained from this equation:

$$
\text { Cleaning efficiency }=\frac{W t-W i}{W t} * 100
$$

$\mathrm{Wt}=$ mass of wheat sample before cleaning and $\mathrm{Wi}=$ mass of impurities (chaff, straw, dirt, pieces of metal and various other foreign bodies) in sample

\section{-The wheat damping}

The wheat damping rate were obtained from this equation:

$$
\text { Wheat damping rate }=\frac{W a-W b}{t} \mathrm{~kg} / \mathrm{h}
$$

$\mathrm{Wb}=$ mass of wheat sample before water addition. $\mathrm{Wa}=$ mass of wheat sample after water addition. $\mathrm{T}=$ damping time.

\section{- The wheat milling}

The first part of the milling process, which is a mechanical process, is to split or break open the wheat grains and to scrape the endosperm away from the bran. This process is repeated several times until it becomes impossible to scrape any more endosperm from the bran. Each time the process is repeated more and more endosperm becomes available and because we are breaking open the wheat grain and releasing its content this process is referred to as the break system 
First break B1 ( $1.65,1.95$ and $2.25 \mathrm{~mm})$ with mesh $1050 \mu$ the standard break release value was $45 \%$, cylinders positions (sharp to sharp, dull to dull, sharp to dull and dull to sharp)

- Second break B2 (1.20,1.50 and $1.80 \mathrm{~mm})$ with mesh $1050 \mu$ the standard break release percentage value was $55 \%$, cylinders positions (sharp to sharp)

- Third break B3 $(0.50,0.80$ and $1.10 \mathrm{~mm})$ with mesh $950 \mu$ the standard break release value was $50 \%$, cylinders positions (sharp to dull)

- Fourth break B4 $(0.45,0.75$ and $1.05 \mathrm{~mm})$ with mesh $300 \mu$ the standard break release value was $50 \%$, cylinders positions (dull to sharp)

\section{RESULTS AND DISCUSSION}

\section{- Tested of some physical properties for wheat kernel}

Table (1). Showed Egyptian wheat (Gemmeiza 9) sample were used have suitable standardizations in length, width and thickness. The length ranged from 6.48 to $7.43 \mathrm{~mm}$, width were 3.16 to 4.02 and seeds thickness ranged from $3.29 \mathrm{~mm}$ to $3.67 \mathrm{~mm}$. while the maximum value of 1000 Grains Weight about $50.60 \mathrm{~g}$ have purities degree between 96 to $98 \%$ and wheat moisture content ranged between 10 to $12 \%$

Table (2). Laboratory Analysis of some physical properties of tested Egyptian wheat samples (Gemmeiza 9).

\begin{tabular}{|l|r|r|c|c|}
\hline Physical properties & \multicolumn{1}{c|}{ Lot 1 } & Lot 2 & Lot 3 & Lot 4 \\
\hline Moisture Content \% & 10.50 & 11.20 & 12.20 & 11.20 \\
\hline Hectoliter Weight Kg/m3 & 80.00 & 78.40 & 77.80 & 77.00 \\
\hline 1000 Grains Weight, g. & 50.00 & 40.00 & 34.60 & 33.80 \\
\hline Thickness of grain mm & 3.67 & 3.29 & 3.35 & 3.35 \\
\hline Width of grain mm & 4.00 & 3.16 & 3.29 & 3.29 \\
\hline Length of grain mm & 7.43 & 6.99 & 7.35 & 7.35 \\
\hline Immature grain \% & 1.13 & 0.50 & 1.77 & 1.50 \\
\hline Foreign matters \% & 0.29 & 0.05 & 0.13 & 0.22 \\
\hline Broken \% & 0.80 & 0.82 & 1.34 & 0.85 \\
\hline
\end{tabular}

\section{Cleaning stage}

The cleaning machines separated the foreign materials (paper, straws, corn, soil etc.) from the grain. 


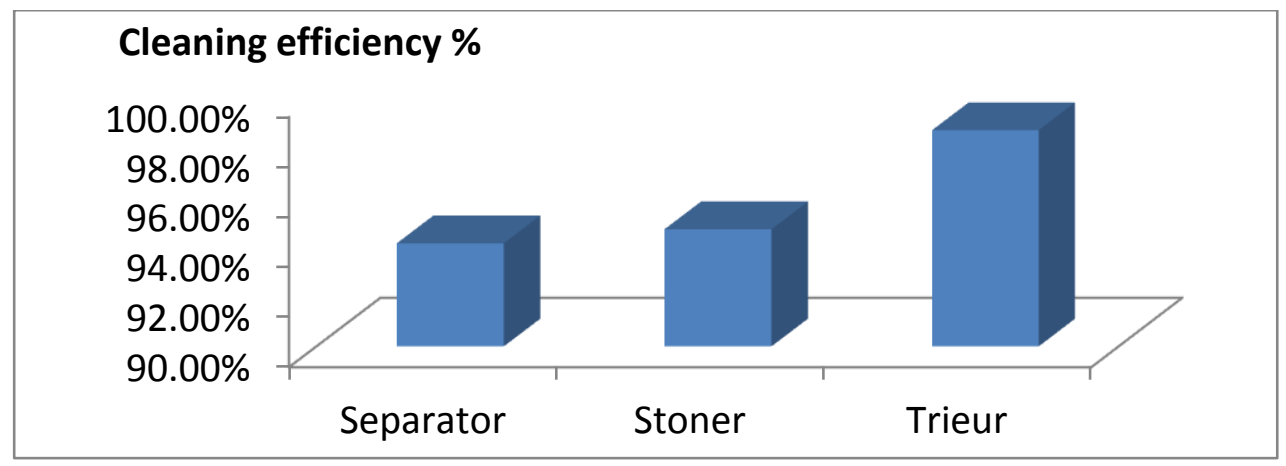

\section{Cleaning efficiency \%}

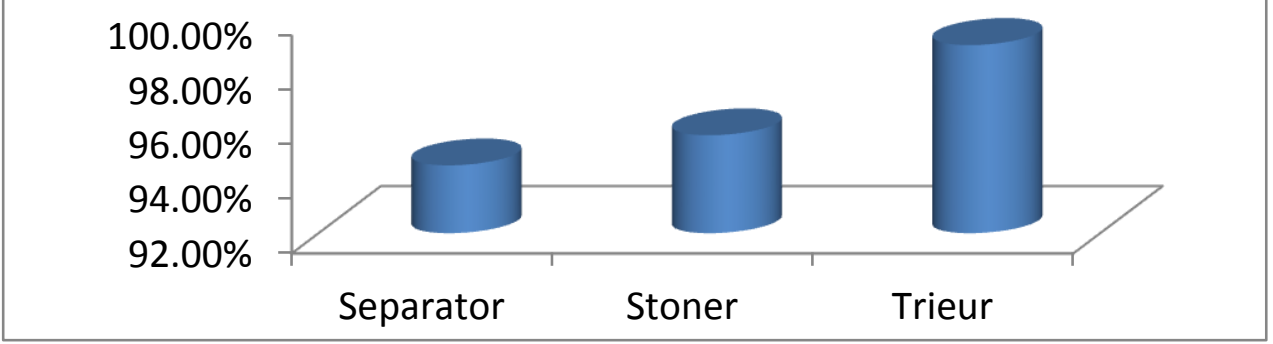

\section{Cleaning efficiency}
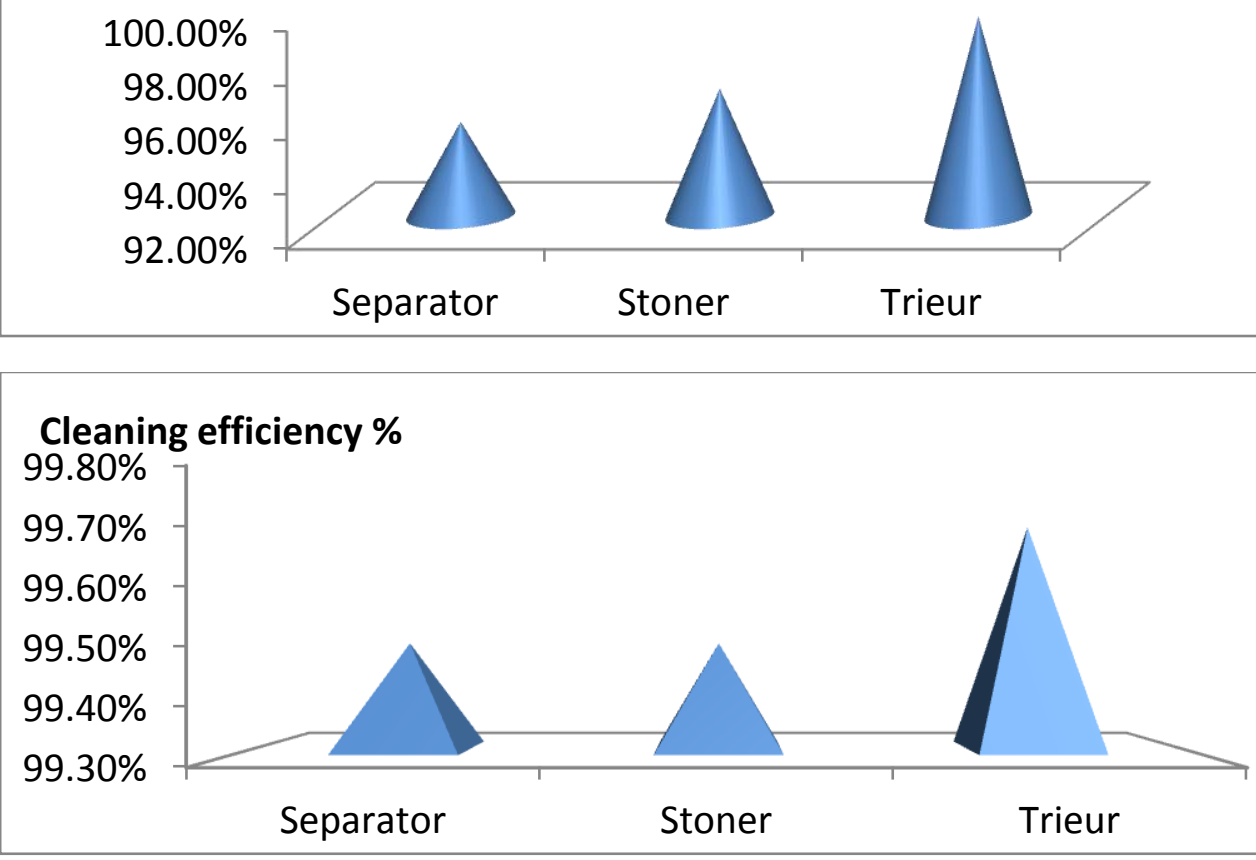

Fig.12: The machines cleaning efficiency at using from Lot 1 to Lot 4 
Fig.12 showing the effect of different cleaning machines, using to cleaning wheat lot, the results clear to the maximum value of cleaning efficiency at the third machine when using Egyptian wheat. The cleaning efficiency ranged from 94.00 to $99.80 \%$. While the minimum value about $94.00 \%$. The cleaning efficiencies for separator, dry stoner and tiruer machine must to be more than $99 \%$

\section{The damping conditioning stage:}

In this stage the water mixes with the all grain lots to get the right moisture level. The results showed in Fig. 13 the moisture content increased form 10.50 to $13.50 \%$ at the first condition to reach $15.5 \%$ at the second condition to \%.Also increased 1000 Grains Weight, form 50.6 to $61.40 \mathrm{~g}$. at the first condition to reach at the second condition to $65.20 \mathrm{~g}$. While hectoliter weight decreased from 80.90 to $78.20 \mathrm{Kg} / \mathrm{m}^{3}$ at the first condition to reach at the second condition to $77.50 \mathrm{Kg} / \mathrm{m}^{3}$.

Milling stage (Break system)

The results in Fig.14 indicate that the values of milling unit at first break B1 ( $1.65,1.95$ and $2.25 \mathrm{~mm})$ with mesh $1050 \mu$ the break test percentage cannot reach to the standard break release value was $45 \%$, the values of break release percentage dissimilar between 42.00 to $45.30 \%$. At the second break B2 $(1.20,1.50$ and $1.80 \mathrm{~mm})$ with mesh $1050 \mu$ the standard break release percentage value was $55 \%$, the break release percentage values have similarity with standard break release percentage for all point unless B2(4) left and right increased to 60.70 and $61.00 \%$ while decrease to 48.70 and $50 \%$ at point B2 (7) left and right respectively the dissimilar between 42.00 to $45.30 \%$. While at Third break B3 $(0.50,0.80$ and $1.10 \mathrm{~mm}$ ) with mesh $950 \mu$ the standard break release value was $50 \%$, the break test percentage cannot reach to the standard break release percentage value the values of break release percentage dissimilar between 48.00 to $59.00 \%$. Finally at fourth break B4 (0.45, 0.75 and 1.05 $\mathrm{mm}$ ) the standard break release percentage value was $30 \%$, the break release percentage values have similarity with standard break release percentage for all point unless B4(1) left and right increased to 39.20 and $38.70 \%$. 
Moisture content, \%

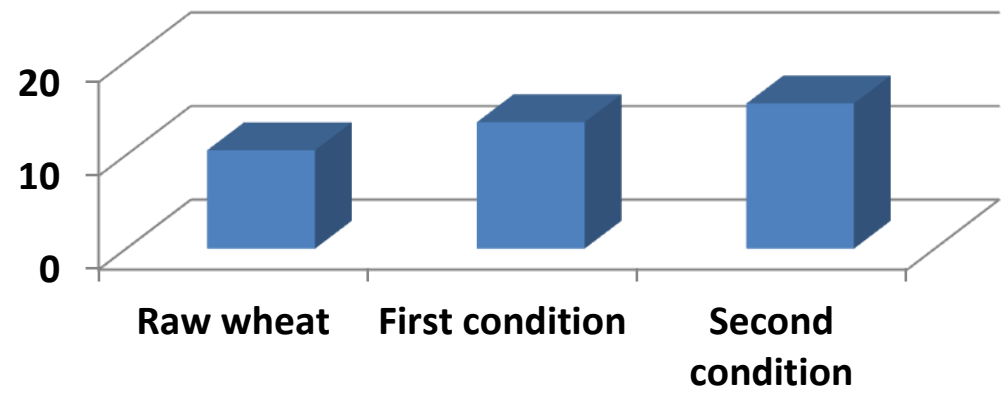

\section{Hectoliter Weight, $\mathrm{Kg} / \mathrm{m3}$}

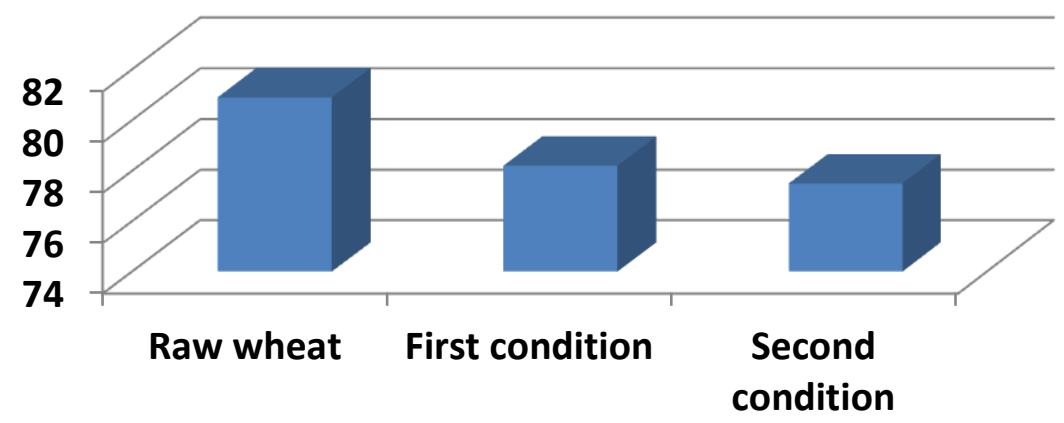

1000 Grains Weight, g.

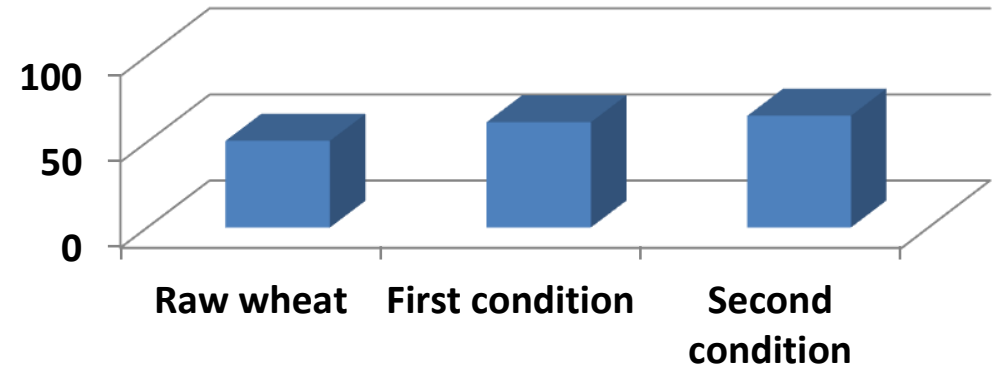

Fig. 13: Effect of tempering conditions on raw wheat moisture content, hectoliter weight and 1000 grains weight 

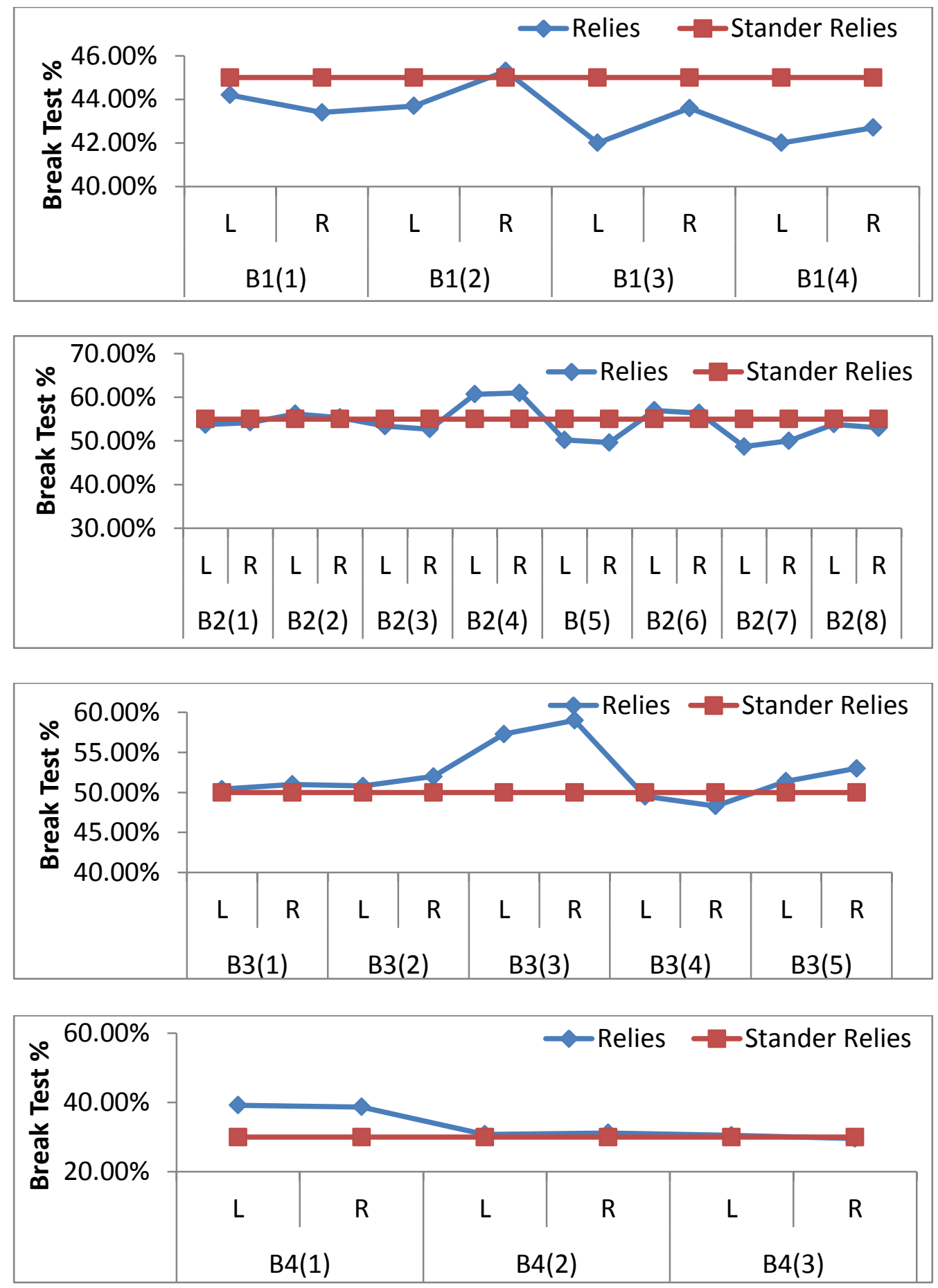

Fig.14: Effect of break system operating (from B1 to B4) on relies flour with stander relies. 


\section{CONCLUSIONS}

To observing the performance of wheat milling production line must know many factors which affecting on the wheat miller performance during milling processes. Some of these factors are related to the wheat quality and others are related to miller machines. The performance of miller must adjusted according to wheat variety and purities degree to adjust cleaning machine also wheat moisture content to adjust amount of water and temping time the choice of break system adjust cylinders clearance and positions to determine the standard break release for each stage. in this case when used Egyptian wheat (Gemmeiza 9) have purities degree between 96 to98\% must adjust the cleaning machines to remove more than $2 \%$ and wheat moisture content ranged between 10 to $12 \%$ must adjust the amount of water and temping time to increase wheat moisture content to reach $15.50 \%$. Also the break system must adjust milling machine to finished the standard break release percentage value with $30 \%$,as the last stge.

\section{REFERANCES}

Campbell, G.M., Fang, C. \& Muhamad, II. (2007a). On predicting roller milling performance VI - Effect of kernel hardness and shape on the particle size distribution from first break milling of wheat. Food and Bio products Processing 85, 7-23

Feillet, P., (2000). Amidon, pentosanes et lipides in Le grain de blé.. (Eds.), INRA edition 147rue de l'université 75338 Paris Cedex 07, 57-90.

Fang, C.Y. and Campbell, G.M. (2002a). Effect of roll fluting disposition and roll gap on breakage of wheat kernels during first-break roller milling.Cereal Chemistry 79, 518-522. 214

Gomez, and Manuel, (2010). Effect of fibre size on the quality of fibreenriched layer cakes." LWT-Food Science and Technology 43.1: 33-38

Johan Karlsson (2008). Department of Signals and Systems. Division of Automatic Control, Automation and Mechatronics. Chalmers University Of Technology Göteborg, Sweden, 2008 Report No. EX055/2008

Kihlberg, I., Johansson, L., Kohler, A., and Risvik, E. (2004). Sensory qualities of whole wheat pan bread-influence of farming system, milling and baking technique. Journal of Cereal Science, 39(1), 67-84. 


\section{الملخص العربي

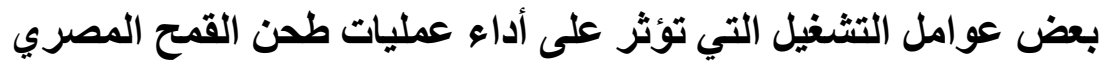

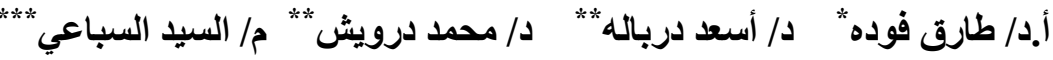

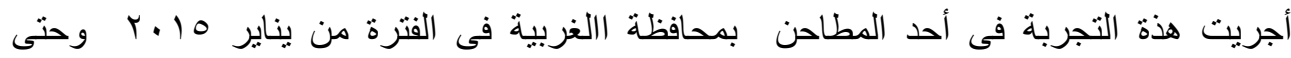

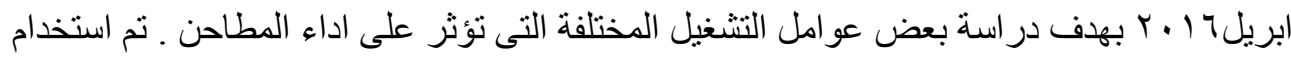

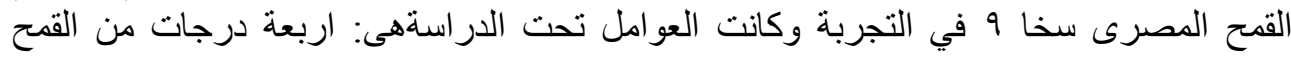

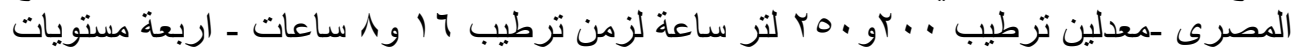

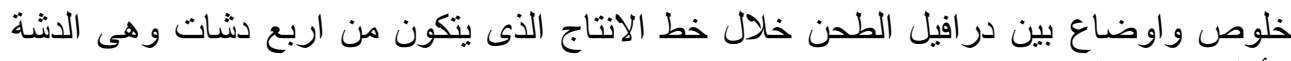

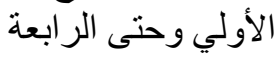

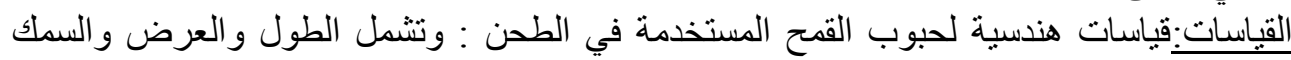

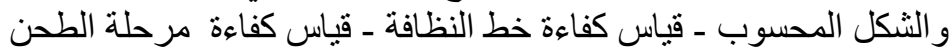

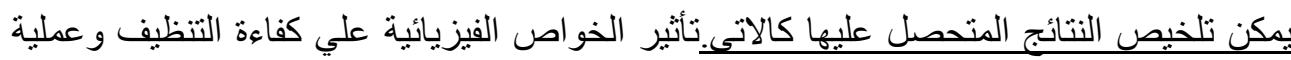

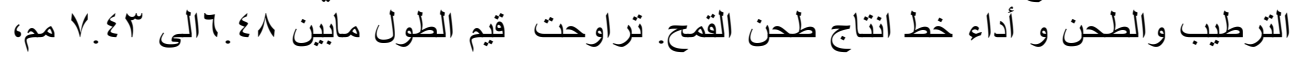

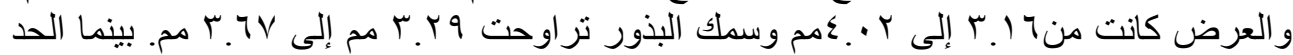

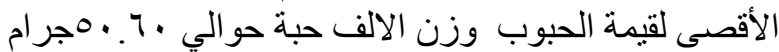

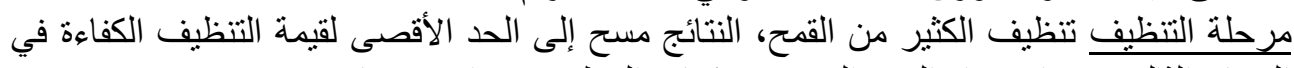

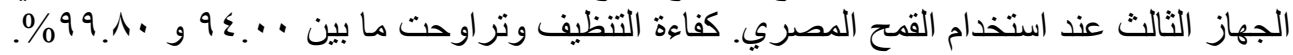

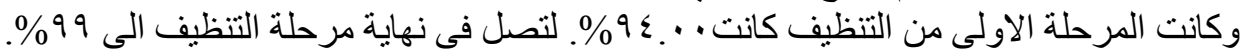

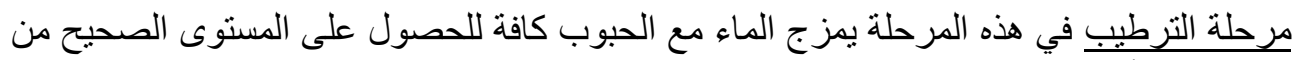

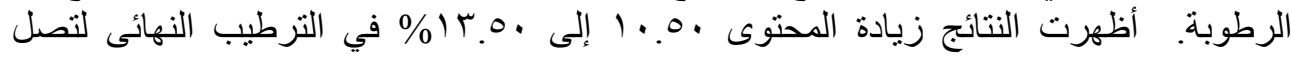

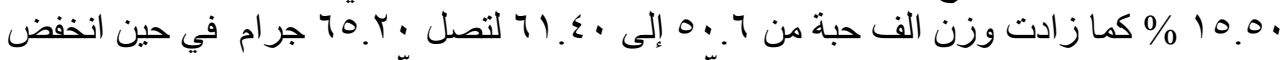

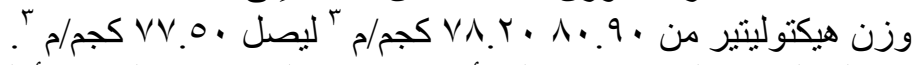

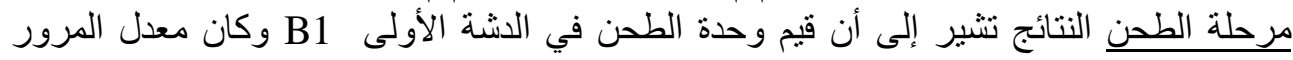

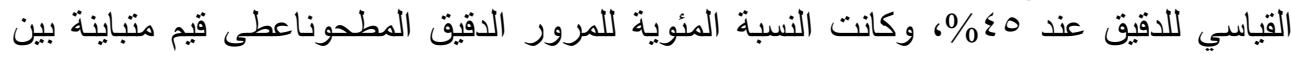

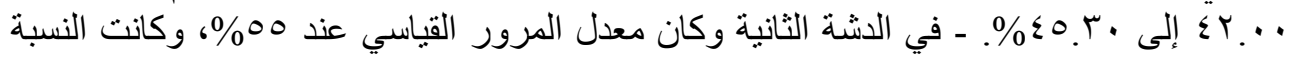

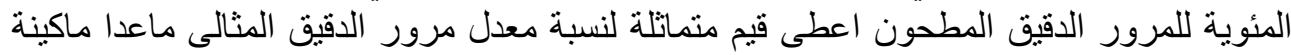

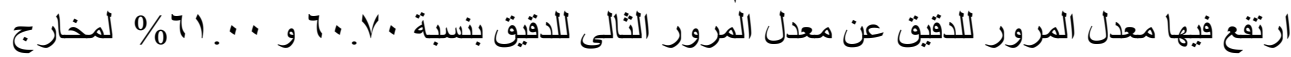

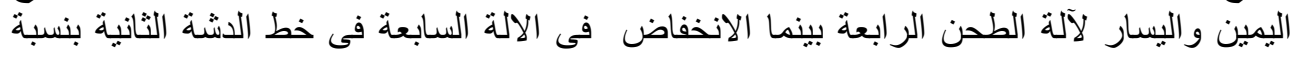

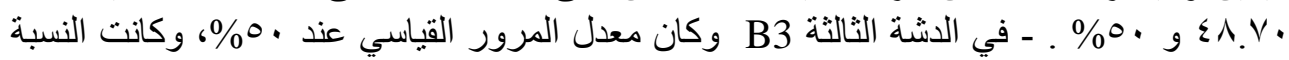
المئوية للمرور الدقيق المطحون اعطى قيم متماتلمة لنسبة معدل مرور معدي الدقيق المثالى ماعدا ماكينة

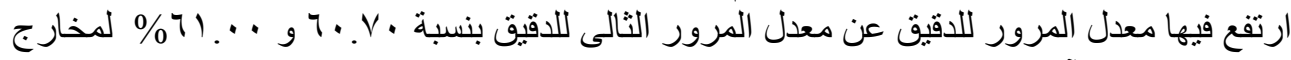

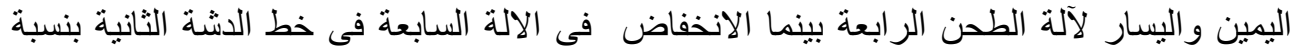

$$
\text { \% \% . . . . . . . }
$$

في الدشة الر ابعة B4 وكان معدل المرور القياسي للاقيق عند • ب\%٪، وكانت النسبة المئوية للمرور

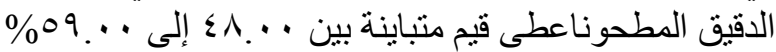

* أستاذ الهندسة الزراعية ـ قسم الهندسة الزراعية ـ كلية الزراعة - جامعة طنطا.

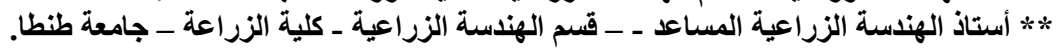

*** * * *الب دراسات عليا ـ - قسم الهندسة الزراعية ـ كلية الزراعة - جامعة طنطا. 